\title{
An autosomal dominant syndrome of renal and anogenital malformations with syndactyly
}

\author{
A J Green, R N Sandford, B C C Davison
}

Abstract

We describe a family with autosomal dominant inheritance of anal anomalies, renal tract abnormalities, genital malformations, and syndactyly. These clinical manifestations do not clearly fall into any previously described syndrome.

A mother and daughter had almost identical congenital malformations, short stature, and unusual facies. The proband was born with anal stenosis, a rectovaginal fistula, clitoral hypertrophy, a pelvic right kidney, and syndactyly of both feet. Her daughter had the same anal, clitoral, and foot anomalies, a solitary pelvic kidney, and no fistula.

This family is likely to represent autosomal dominant inheritance of a new combination of malformations, which may overlap with the Townes-Brocks syndrome, but does not fall into a current diagnostic category.

( $\mathcal{H}$ Med Genet 1996;33:594-596)

Key words: anal anomalies; syndactyly; renal adysplasia.

There are numerous clinical syndromes associated with anal anomalies, of which few are inherited in an autosomal dominant pattern.

Department of Clinical Genetics, Addenbrooke's NHS

Trust, Cambridge, UK A J Green

R N Sandford

B C C Davison

Department of Medical Genetics, University of Cambridge, UK A J Green

Correspondence to: Dr Green, Department of Medical Genetics, Box 134, Addenbrooke's NHS Trust, Cambridge CB2 2QQ, UK

Received 24 August 1995 Revised version accepted for publication 27 February 1996

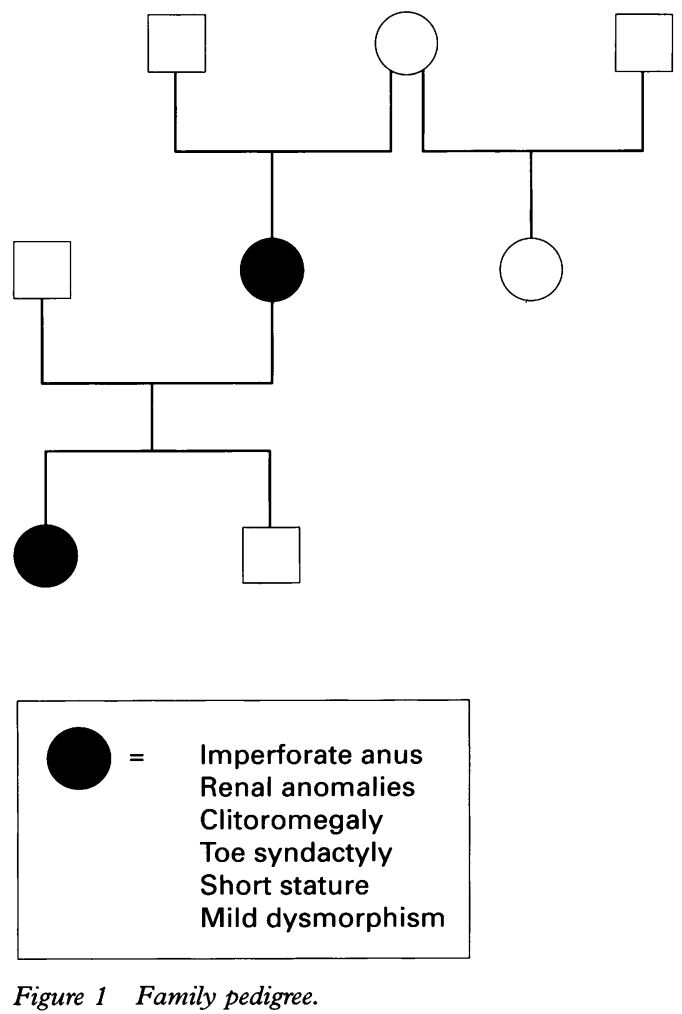

Such dominant conditions include the TownesBrocks syndrome ${ }^{1}$ and the ASP syndrome (also known as the triad of Currarino). ${ }^{2}$ Autosomal dominant inheritance of isolated anal anomalies has also been described. ${ }^{3}$ Sporadic occurrence of anal anomalies with malformations of other organs can occur in several syndromes, including VATER syndrome and caudal dysgenesis. ${ }^{45}$ Dominant inheritance of anorectal malformations has also been described, with anal stenosis and rectovaginal fistulae in a mother and two daughters. ${ }^{6}$ A single family with dominant inheritance of caudal dysgenesis has been described. ${ }^{7}$

We describe a family which does not easily fit in any such diagnostic categories. They show dominant inheritance of anal, renal, and genital anomalies with syndactyly.

\section{Case report}

The female proband (II·2, fig 1) was born after a normal pregnancy and delivery and was noted to have anal stenosis, significant clitoromegaly, and passed meconium per vaginam. She had 3-5 soft tissue syndactyly of her left foot and 4-5 syndactyly of her right foot (fig 2, top), with normal hands, and no clinical craniosynostosis She had an anoplasty, repair of a rectovaginal
Figure 2 (Top) Feet of II $\cdot 2$ showing left 3-5 syndactyly left 3-5 syndactyly and right 2-5 syndactyly. and right 4-5 syndactyly. (Bottom) Feet of III 1 showing 
fistula, and a reduction clitoroplasty shortly after birth. Biochemical investigation of adrenal function was normal. She had normal internal female reproductive organs. Subsequently, she had urinary tract infections and was found to have a pelvic right kidney, hydronephrosis of a normally placed left kidney, and a small unstable bladder. She eventually required an ileoenterocystoplasty and a ureteroplasty. She was also noted to have an asymptomatic ventricular septal defect. She was mildly dysmorphic, with a narrow nose, a square broad forehead, and normal ears, with no ear folds. Unfortunately, confidentiality does not permit the publication of facial photographs in this case and her daughter.

She was the first child of unrelated white parents, with no significant family history. She had a healthy, older paternal half sister. Significant short stature was noted at 3 years of age, and she attained an adult height of $146 \mathrm{~cm}$, below both the 3 rd centile and her expected midparental height. She had normal schooling with no learning difficulties. Menarche was at the age of 12 , with normal secondary sexual development.

At the age of 20, she was seen by the clinical genetics service. Chromosome analysis was normal and no specific diagnosis was made; an empirical $5 \%$ recurrence risk was given for her offspring.

At the age of 22, she became pregnant, and after a normal pregnancy gave birth to a daughter (III-1) with anal stenosis, significant clitoromegaly, 3-5 syndactyly of the left foot, and 2-5 syndactyly of the right foot (fig 2, bottom). She had unilateral renal agenesis with a solitary pelvic kidney. She did not have a rectovaginal fistula. She also had bilateral fifth finger clinodactyly. As with her mother, she had an anoplasty and clitoral reduction. She has similar features to her mother and her ears are not malformed. At 18 months of age, she is well below the 3rd centile for weight, length, and head circumference, but has normal developmental milestones.

Subsequently, after being advised of a $50 \%$ recurrence risk, the proband had a second child, who is a normally developed male with no congenital malformations. He is developing along the 50th centile for height and weight.

\section{Discussion}

Congenital anal and pelvic anomalies are relatively common, but rarely recur. Families with autosomal dominant anal stenosis without other malformations have been described. ${ }^{3}$ The spectrum of malformations in our family would exclude this diagnostic category. There are several syndromes which could be included in the differential diagnosis for our families, but no previously described cases clearly fit.

Boocock and Donnai ${ }^{8}$ have reviewed 169 consecutive children with anorectal malformations, and found that 15 had a family history of congenital malformations. Five of these cases had a family history of uncomplicated anal stenosis or atresia. Ten cases had associated malformations themselves, with
Comparison of the features of Townes-Brocks syndrome with current family

\begin{tabular}{lll}
\hline Malformation & $\begin{array}{l}\text { Townes-Brocks } \\
\text { syndrome }\end{array}$ & $\begin{array}{l}\text { Present } \\
\text { family }\end{array}$ \\
\hline Imperforate anus & + & + \\
Thumb anomaly & + & - \\
External ear anomaly & + & - \\
Deafness & + & - \\
Renal anomaly & + & + \\
Cardiac anomaly & + & + \\
Ulnar syndactyly & - & + \\
Genital anomaly & - & + \\
Short stature & - & + \\
\hline
\end{tabular}

a family history of similar malformations. These consisted of limb reduction deformities, cogenital heart disease, and renal malformations. None of these cases resemble the family we present, although II 2 did have an asymptomatic VSD, and one reported case had toe webbing and facial asymmetry.

Autosomal dominant renal adysplasia has been reported, and shows non-penetrance and variable expression, including unilateral renal agenesis. ${ }^{9}$ Familial occurrence of renal aplasia and vaginal atresia has been described, ${ }^{10}$ and the term hereditary urogenital adysplasia has been suggested. ${ }^{11}$ It has been proposed that this condition may be related to the von MayerRokitansky-Kuster syndrome of vaginal atresia. ${ }^{12}$ Significant clitoromegaly and anal abnormalities have not been described in these associations, and these diagnoses are therefore not sustainable in our family.

The ASP syndrome shows autosomal dominant inheritance of anal anomalies, sacral agenesis or hypoplasia, and a presacral tumour. ${ }^{2}$ Renal and limb abnormalities have not been described in this clinical classification. Anal anomalies are a feature of the cat eye syndrome, associated with a marker chromosome 22 , but the karyotype was normal in both families. A single family with renal, genital, and anal anomalies as part of the spectrum of caudal dysgenesis was described by Rudd and Klimek. ${ }^{7}$ This is unlikely to be similar to our family, as there was no clear sacral anomaly in our families, and syndactyly is not a feature of caudal dysgenesis. VATER syndrome has a clinical overlap with sacral dysgenesis, but our family had no radial lesions and no tracheo-oesophageal fistula. Genital anomalies are not a feature of VATER syndrome.

The diagnosis of Townes-Brocks syndrome comes closest in our families, but is not correct for a number of reasons (table). None of our patients had the characteristic ear malformations, nor were they deaf. The type of syndactyly we describe has not been described in Townes-Brocks syndrome. Renal hypoplasia had been described in Townes-Brocks syndrome $^{1314}$ as has unilateral renal agenesis, ${ }^{1516}$ and it is interesting to note that $\mathrm{II} \cdot 2$ in the family we report had an asymptomatic ventricular septal defect. However, genital abnormalities and short stature are not a feature of that condition. The well described variability of expression of Townes-Brocks syndrome does make complete exclusion of this diagnosis difficult. ${ }^{1}$ 
The nature of the genetic defect responsible for this syndrome is unclear. It is interesting to note the recent description of autosomal dominant renal anomalies and colobomas in association with mutations of the PAX2 gene. ${ }^{17}$ Other members of the PAX or related gene families may be responsible for autosomal dominant renal anomalies in association with ana and genital malformations.

We describe a family with autosomal dominant inheritance of renal, anal, and genital abnormalities, in association with syndactyly, short stature, and mild dysmorphology. This syndrome is not easily categorised into a previously described condition and further extends the spectrum of conditions associated with autosomal dominant anal anomalies.

We are grateful to Dr R D Jones for referring the family.

1 O'Callaghan M, Young ID. The Townes-Brocks syndrome. 7 Med Genet 1990;27:457-61.

2 Currarino $\mathrm{G}$, Coln D, Votteler T. Triad of anorectal, sacral and presacral anomalies. $A \mathscr{F} R$ 1981;137:395-8.

3 Cozzi F, Wilkinson AW. Familial incidence of congenital anorectal anomalies. Surgery 1968;64:669-71.

4 Weaver DD, Mapstone CL, Yu PL. The VATER association. Am $\mathcal{F}$ Dis Child 1986;140:225-9.
5 Duncan PA, Shapiro LR, Klein RM. Sacrococcygeal dysgenesis association. Am f Med Genet 1991;41:153-61.
Kaijser K, Malmstrom-Groth A. Anorectal anomalies a congenital familial incidence. Acta Paediatr 1957;46:

7 Rudd NL, Klimek ML. Familial caudal dysgenesis: evidence for a major dominant gene. Clin Genet 1990;38:170-5.

8 Boocock GR, Donnai D. Anorectal malformation: familial aspects and associated anomalies. Arch Dis Child 1987; 62:576-9.

9 McPherson E, Carey J, Kramer A, et al. Dominantly in herited renal adysplasia. Am f Med Genet 1987;26:863-72.

10 Winter JSD, Kohn G, Mellman WJ, Wagner S. A familial syndrome of renal, genital and middle ear anomalies. $f$ Pediatr 1968;72:88-93.

11 Schimke RN, King CR. Hereditary urogenital adysplasia Clin Genet 1980;18:417-20.

12 Opitz JM. Vaginal atresia (von Mayer-Rokitansky-Kuster or MRK anomaly) in hereditary renal adysplasia (HRA) Am MRed Genet 1987;26:873-6.

13 De Vries-Vand Der Weerd MACS, Willems P, Mandema HM, Ten Kate LP. A new family with the Townes-Brocks syndrome. Clin Genet 1988;34:195-200.

14 Kurnit DM, Steele MW, Pinsky L, Dibbins A. Autosoma dominant transmission of a syndrome of anal, ear, renal and radial congenital malformations. $\mathcal{F}$ Pediatr $1978 ; 100$ 250-2.

15 Barakat AY, Butler MG, Salter JE, Fogo A. Townes-Brocks syndrome: report of three additional patients with previously undescribed renal and cardiac anomalies. Dysmorphol Clin Genet 1988;2:104-8.

16 Ferraz FG, Nunes L, Ferraz ME, et al. Townes-Brocks syndrome. Report of a case and review of the literature. syndrome. Report of a case and re
Ann Genet (Paris) 1989;32:120-33

17 Sanyanusin P, Schimmenti LA, McNoe LA, et al. Mutation of the PAX2 gene in a family with optic nerve colobomas, renal anomalies and vesicoureteral reflux. Nature Genet 1995;9:358-64. 